\title{
Muscarinic Receptor Modulation of Slow Afterhyperpolarization and Phasic Firing in Rat Supraoptic Nucleus Neurons
}

\author{
Masoud Ghamari-Langroudi and Charles W. Bourque \\ Centre for Research in Neuroscience, Montreal General Hospital and McGill University, Montreal, Quebec H3G 1A4, Canada
}

\begin{abstract}
A slow posttrain afterhyperpolarization (sAHP) was studied in rat magnocellular neurosecretory cells (MNCs) in vitro. The sAHP was isolated from other afterpotentials by blocking the depolarizing afterpotential (DAP) with $\mathrm{Cs}^{+}$and the medium afterhyperpolarization (mAHP) with apamin. The sAHP amplitude increased logarithmically with activity ( $\sim 3 \mathrm{mV}$ per $e$-fold increase in number of impulses) and, when firing stopped, decayed exponentially with a time constant of $2 \mathrm{sec}$. The sAHP was associated with increased membrane conductance, and its amplitude varied linearly with voltage, reversing at the $\mathrm{K}^{+}$equilibrium potential. The sAHP was blocked by $\mathrm{Cd}^{2+}$ but not by charybdotoxin or iberiotoxin, blockers of intermediate- and big-conductance-type $\mathrm{Ca}^{2+}$-dependent $\mathrm{K}^{+}\left(\mathrm{K}_{\mathrm{Ca}}\right)$ channels. The sAHP was reversibly inhibited by muscarine, an effect antagonized by atropine, indicating involvement of muscarinic cholinergic receptors. Muscarine did not affect $\mathrm{Ca}^{2+}$-dependent features of action potentials, DAPs, or the mAHP in MNCs, indicating selective modulation of $\mathrm{K}_{\mathrm{Ca}}$ channels causing the sAHP. Muscarinic inhibition of the SAHP enhanced plateau potentials and increased the mean firing rate and duration of afterdischarges that followed spike trains evoked from voltages near threshold. Similarly, the frequency and duration of the spontaneous phasic bursts that characterize physiologically activated vasopressin-releasing MNCs were enhanced by muscarine. MNCs thus express apamin- and voltage-insensitive $\mathrm{K}_{\mathrm{Ca}}$ channels that mediate an sAHP. The activity dependence and kinetics of the sAHP cause it to mask DAPs in a manner that attenuates the amplitude of plateau potentials. Muscarinic inhibition of the sAHP provides an effective mechanism for promoting phasic firing in MNCs.
\end{abstract}

Key words: vasopressin; supraoptic; afterdischarge; neurohypophysis; burst; muscarinic

\section{Introduction}

The release of vasopressin (VP) into blood is controlled by the electrical activity of magnocellular neurosecretory cells (MNCs) in the supraoptic and paraventricular nuclei of the hypothalamus (Renaud and Bourque, 1991). Increases in action potential firing rate enhance VP secretion from neurohypophysial nerve endings by raising the number of impulses triggering exocytosis and by potentiating the amount of peptide secretion per impulse (Dreifuss et al., 1971). Furthermore, VP release displays reversible fatigue during continuous stimulation (Bicknell, 1988). Thus, secretion is maximized by rhythmic bursting (Dutton and Dyball, 1979; Bicknell and Leng, 1981). Indeed, under conditions demanding high plasma VP concentrations (e.g., hyperosmolality), MNCs adopt phasic firing, a pattern comprising alternating periods of activity and silence lasting tens of seconds each (Harris et al., 1975; Brimble and Dyball, 1977; Wakerley et al., 1978).

The mechanisms involved in modulating the expression of phasic firing are not known. However, it has been reported that

Received April 2, 2004; revised July 19, 2004; accepted July 19, 2004.

This work was supported by Canadian Institutes of Health Research (CIHR) Operating, CIHR Senior Investigator, and James McGill Research awards to C.W.B.

Correspondence should be addressed to Dr. Charles W. Bourque, Division of Neurology, Montreal General Hospital, 1650 Cedar Avenue, Room L7-216, Montreal, QC H3G 1A4, Canada. E-mail: charles.bourque@mcgill.ca. DOI:10.1523/JNEUROSCI.1240-04.2004

Copyright $\odot 2004$ Society for Neuroscience $\quad$ 0270-6474/04/247718-09\$15.00/0 exogenously applied acetylcholine can promote phasic firing from MNCs in vivo (Bioulac et al., 1978; Arnauld et al., 1983) and in vitro (Hatton et al., 1983), and that preoptic cholinergic neurons projecting axons to the supraoptic nucleus become activated under hyperosmotic conditions (Xu et al., 2003). Effects of acetylcholine on phasic firing could be mediated by either nicotinic or muscarinic receptors. Indeed, recent work has shown that MNCs can be depolarized by postsynaptic nicotinic receptors comprising the $\alpha 7$ subunit (Zaninetti et al., 2000; Hatton and Yang, 2002). Muscarinic receptors, however, are also expressed in the supraoptic nucleus (Rotter et al., 1979), and activation of such receptors by endogenously released acetylcholine has been shown to stimulate Fos production in MNCs (Takahashi et al., 2001).

The possibility that acetylcholine might regulate phasic firing via the activation of muscarinic receptors in MNCs is further supported by studies in other neurons showing that such receptors can promote burst firing by enhancing plateau potentials (Alonso et al., 1994; Kawasaki et al., 1999). In MNCs, plateau potentials arising from summation of slow $(3-6 \mathrm{sec})$ postspike depolarizing afterpotentials (DAPs) are required for the onset and maintenance of firing during phasic bursts (Andrew and Dudek, 1984; Ghamari-Langroudi and Bourque, 1998). Although different combinations of conductances underlie plateaus in different cells (Kiehn and Eken, 1998), enhancement of plateaus by muscarinic agonists is commonly achieved through 
the inhibition of calcium-activated $\mathrm{K}^{+}\left(\mathrm{K}_{\mathrm{Ca}}\right)$ channels responsible for a slow $(2-5 \mathrm{sec})$ posttrain afterhyperpolarization (sAHP) (Alonso et al., 1994; Kawasaki et al., 1999). Interestingly, a recent study has suggested that MNCs can generate an SAHP after prolonged spike trains (Greffrath et al., 1998). However, the ionic basis for this sAHP is not clear, and it is not known how the activity dependence of the sAHP differs from that of the briefer, apamin-sensitive afterhyperpolarization that is also expressed in MNCs (Bourque and Brown, 1987; Kirkpatrick and Bourque, 1996). In this study, we characterized the properties of the sAHP in MNCs and showed that its selective inhibition by muscarinic cholinergic receptors provides an effective means of enhancing plateau potentials and phasic firing.

\section{Materials and Methods}

Preparation of superfused explants. Hypothalamic explants were prepared as described previously (Ghamari-Langroudi and Bourque, 1998). Briefly, male Long-Evans (L.E.) rats (150-300 gm) were killed by decapitation according to a protocol approved by the Animal Care Committee of McGill University. The brain was rapidly removed, and a block of tissue $(\sim 8 \times 8 \times 2 \mathrm{~mm})$ comprising the basal hypothalamus was excised using razor blades and transferred to a temperature-controlled $\left(31-33^{\circ} \mathrm{C}\right)$ superfusion chamber. Explants were superfused $(0.5-1 \mathrm{ml} /$ min) with an oxygenated $\left(95 \% \mathrm{O}_{2}-5 \% \mathrm{CO}_{2}\right)$ artificial cerebrospinal fluid (ACSF) (pH 7.4; $295 \pm 1 \mathrm{mOsmol} / \mathrm{kg}$ ) composed of (in mM): $121 \mathrm{NaCl}$, $1.3 \mathrm{MgCl}_{2}, 3 \mathrm{KCl}, 26 \mathrm{NaHCO}_{3}, 10$ glucose, and $2.5 \mathrm{CaCl}_{2}$ (all from Fisher Scientific, Nepean, Ontario, Canada).

Drugs and channel blockers. Stock solutions of $10^{-4} \mathrm{M}(+)$ muscarine chloride, $10^{-4} \mathrm{M}$ atropine sulfate, $1 \mathrm{M} \mathrm{CsCl}, 0.5 \mathrm{M} \mathrm{CdCl}_{2}$, and $0.5 \mathrm{~mm}$ tetrodotoxin (all from Sigma, St. Louis, MO) were prepared by dissolving the drugs in distilled water and were kept at $4^{\circ} \mathrm{C}$ until use. Stock solutions of $10^{-4} \mathrm{M}$ apamin (Sigma), $2 \times 10^{-5} \mathrm{M}$ charybdotoxin (ChTx) (Sigma or Alomone Labs, Jerusalem, Israel), and $10^{-5} \mathrm{M}$ iberiotoxin (IBTX) (Sigma) were prepared by dissolving the peptide in distilled water and storing individual aliquots at $-20^{\circ} \mathrm{C}$ until use. The effects of the drugs were examined by bath application of dilutions of stock in ACSF. In some experiments, $0.01 \%$ bovine serum albumin (BSA) (Sigma) was added to the ACSF to occlude nonspecific binding sites in the apparatus before and during application of charybdotoxin or iberiotoxin. As reported in the text, no effects of these compounds were observed whether BSA was present or not.

Electrophysiology. Intracellular recordings were obtained using sharp microelectrodes prepared from $1.2 \mathrm{~mm}$ outer diameter glass capillary tubes (A-M Systems, Everett, WA) pulled on a P87 Flaming-Brown pipette puller (Sutter Instruments, Novato, CA) and filled with $2 \mathrm{M}$ potassium acetate (yielding resistances, $70-150 \mathrm{M} \Omega$ ). Recordings of membrane voltage (DC, $5 \mathrm{kHz}$ ) and current (DC, $0.3 \mathrm{kHz}$ ) were obtained using an Axoclamp 2A amplifier (Axon Instruments, Union City, CA). Signals were displayed on a chart recorder and digitized $(44 \mathrm{kHz}$; Neurodata Instruments, New York, NY) for storage onto videotape. Current pulses were delivered through an external pulse generator or via a Digidata 1200B interface driven by pCLAMP 8.0 software (Axon Instruments) running on an Pentium III computer. Averaging, digital subtraction, and exponential fitting of data traces were performed using Clampfit 8 (Axon Instruments).

Protocols used to elicit afterpotentials. Because plateau potentials are initiated by the summation of postspike DAPs (Andrew and Dudek, 1984; Ghamari-Langroudi and Bourque, 1998), they can be evoked reliably by trains of action potentials elicited by either of the following: (1) a train of brief ( $4 \mathrm{msec} ; 300-600 \mathrm{pA}$ ) depolarizing current pulses that each trigger a single impulse or (2) a single, more prolonged (40-2500 msec) depolarizing current pulse. In this study, both methods were used to evoke afterpotentials. Previous experiments have shown that the amplitude of plateaus after trains of action potentials is affected by the number of spikes in a train (Andrew and Dudek, 1984) and the membrane potential from which it is evoked ( $\left.V_{\text {INITIAL }}\right)$ (Bourque, 1986). Plateaus were therefore evoked using trains comprising constant numbers of action potentials triggered from a constant $V_{\text {INITIAL }}(<1 \mathrm{mV}$ variation between trials) that was adjusted by DC current injection $(0-100 \mathrm{pA})$, if necessary. The value of $V_{\text {INITIAL }}$ varied between -66 and $-55 \mathrm{mV}$ in different cells. Moreover, because plateau amplitude is attenuated by preceding action potential activity (Andrew and Dudek, 1984), successive trials were evoked at a low frequency $(<0.05 \mathrm{~Hz})$, and spontaneous firing, when present, was prevented by holding $V_{\text {INITIAL }}$ below spike threshold. To study the activity dependence of the SAHP, a minimum of 10 trains (in most cases $>30$ ) comprising 1-70 impulses were evoked in each cell. For each cell, we then calculated the amplitude of the sAHP evoked by trains comprising an even number of impulses (i.e., 2, 4, 6,. . 70) by linear interpolation of the data. The corresponding average amplitude of the sAHP was then calculated from values derived from all of the cells.

Measurement of membrane potential in active cells. The resting membrane potential observed during phasic bursts was defined as the mean stationary voltage observed during interspike intervals, excluding the decaying phase of the fast afterhyperpolarization (fAHP) and depolarizing ramps that, respectively, follow and precede individual action potentials. However, the detection of stationary pauses becomes difficult during periods of relatively fast firing $(5-15 \mathrm{~Hz})$. We therefore determined the mean plateau voltage as described previously (Ghamari-Langroudi and Bourque, 2000). Briefly, all-points histograms (bin width, 0.04-0.1 $\mathrm{mV}$ ) of voltage excerpts digitized at $4-5 \mathrm{kHz}$ (4-10 sec long) were constructed using Fetchan 6.0 (Axon Instruments). The frequency distribution of the voltage samples obtained in this manner showed two clear peaks. The most negative peak registered the brief stationary phase at the peak of the fAHP, whereas a larger, slightly more depolarized peak reflected the stationary phases interspersed in the recording. Plateau voltage during firing was thus defined as the voltage corresponding to this peak.

Statistics. Throughout this paper, averaged data are expressed as mean \pm SEM, the only exception being the variance of the activity dependence of sAHP activation (see Fig. 3B), which is displayed by expressing the data as mean $\pm \mathrm{SD}$. Differences between means were evaluated using an unpaired or paired $t$ test, as appropriate, and were considered significant when $p<0.05$.

\section{Results}

Intracellular recordings with sharp microelectrodes were obtained from neurons in the ventrocaudal part of the supraoptic nucleus in superfused hypothalamic explants prepared from adult male L.E. rats. The cells retained for analysis had resting membrane potentials more negative than $-50 \mathrm{mV}$, input resistances exceeding $150 \mathrm{M} \Omega$ (slope resistance below $-70 \mathrm{mV}$ ), and fired action potentials whose amplitude was $>60 \mathrm{mV}$ when measured from baseline. These cells also displayed frequencydependent spike broadening and transient outward rectification when examined from initial membrane potentials below -75 $\mathrm{mV}$. These properties characterize MNCs in the supraoptic nucleus but not neighboring non-neuroendocrine cells (Dyball et al., 1991; Renaud and Bourque, 1991). Previous studies have shown that almost $70 \%$ of the neurons in the supraoptic nucleus of L.E. rats contain vasopressin (Rhodes et al., 1981). Moreover, compared with oxytocin-containing neurons, which cluster rostrodorsally, vasopressinergic MNCs tend to be concentrated in the ventral and caudal parts of the nucleus. Thus, although this was not verified directly (e.g., by intracellular marking and postrecording immunocytochemistry), it is likely that most of our recordings were obtained from VP-releasing MNCs.

\section{Isolation of the SAHP}

Previous studies in MNCs have shown that the afterhyperpolarization that follows a brief spike train evoked by a current pulse (e.g., two to four action potentials evoked by an $80 \mathrm{msec}$ depolarizing pulse) can be blocked by apamin (Bourque and Brown, 1987; Armstrong et al., 1994; Kirkpatrick and Bourque, 1996; 

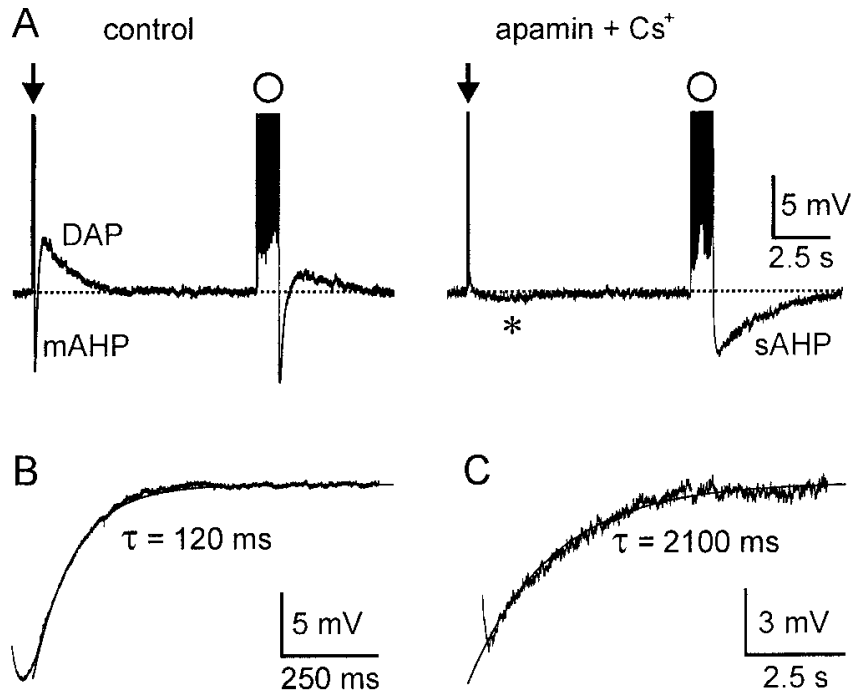

Figure 1. Isolation of the SAHP in MNCs. A, Intracellular recordings showing voltage responses of an MNC after brief (arrow, 3 spikes evoked by a 50 msec current pulse) and long (circle, 30 impulses evoked by a 1.5 sec pulse) spike trains under control conditions (left) and in the presence of $100 \mathrm{~nm}$ apamin and $5 \mathrm{~mm} \mathrm{Cs}{ }^{+}$(right). Note that, in apamin and Cs ${ }^{+}$, a slow AHP is barely visible after the brief train (asterisk) but is prominent after the long train. B, Subtraction of traces obtained in control and apamin reveals the time course of decay of the apaminsensitive $\mathrm{mAHP}$ that follows a brief train. The trace is superimposed by a monoexponential fit through the points, and the time constant $(\tau)$ is indicated. C, The decaying phase of the sAHP recorded after a long train applied in the presence of $\mathrm{Cs}^{+}$and apamin is shown superimposed with a monoexponential fit through the data points.

Greffrath et al., 1998), and that the DAP and plateau potential can be blocked by $\mathrm{Cs}^{+}$(Ghamari-Langroudi and Bourque, 1998). Because a slow apamin-insensitive sAHP appears to be evoked primarily by long trains of action potentials (Greffrath et al., 1998), we hypothesized that the sAHP could be isolated from the apamin-sensitive afterhyperpolarization and DAPs by evoking long trains of action potentials in the presence of $5 \mathrm{~mm} \mathrm{Cs}^{+}$and $100 \mathrm{~nm}$ apamin. We therefore compared the effects of these drugs on the afterpotentials that followed brief (two to five action potentials) and long (20-40 action potentials) spike trains (see Materials and Methods). Under control conditions, brief spike trains evoked a brief ( $\sim 200 \mathrm{msec})$ afterhyperpolarization followed by a slower $(2-5 \mathrm{sec})$ plateau, whereas long spike trains evoked a slightly more prolonged afterhyperpolarization ( $\sim 500 \mathrm{msec})$ followed by an attenuated plateau (Fig. $1 A$ ). In the presence of 100 $\mathrm{nm}$ apamin and $5 \mathrm{mM} \mathrm{Cs}^{+}$, both the brief afterhyperpolarization and the plateau that followed short trains were abolished, and an sAHP of much smaller amplitude was occasionally unmasked $(n=5)$ (Fig. $1 A$, asterisk). In contrast, long spike trains evoked in the presence of $\mathrm{Cs}^{+}$and apamin were followed by a prominent sAHP lasting $>5 \mathrm{sec}$ (Fig. $1 A$ ). These observations suggest that trains comprising two to five spikes elicit primarily an afterhyperpolarization that is caused by the activation of apamin-sensitive $\mathrm{K}_{\mathrm{Ca}}$ channels, but that longer spike trains can evoke an apamininsensitive sAHP. We showed previously that the time course of the afterhyperpolarization that follows a train of action potentials is affected by the decay of the overlapping plateau potential (Ghamari-Langroudi and Bourque, 1998). Thus, to examine the decay kinetics of the isolated apamin-sensitive afterhyperpolarization, we subtracted voltage traces recorded in the presence of apamin from those recorded under control conditions (Fig. $1 B$ ). The mean time constant of decay of the apamin-sensitive afterhyperpolarization elicited by brief spike trains was $149 \pm 14 \mathrm{msec}$
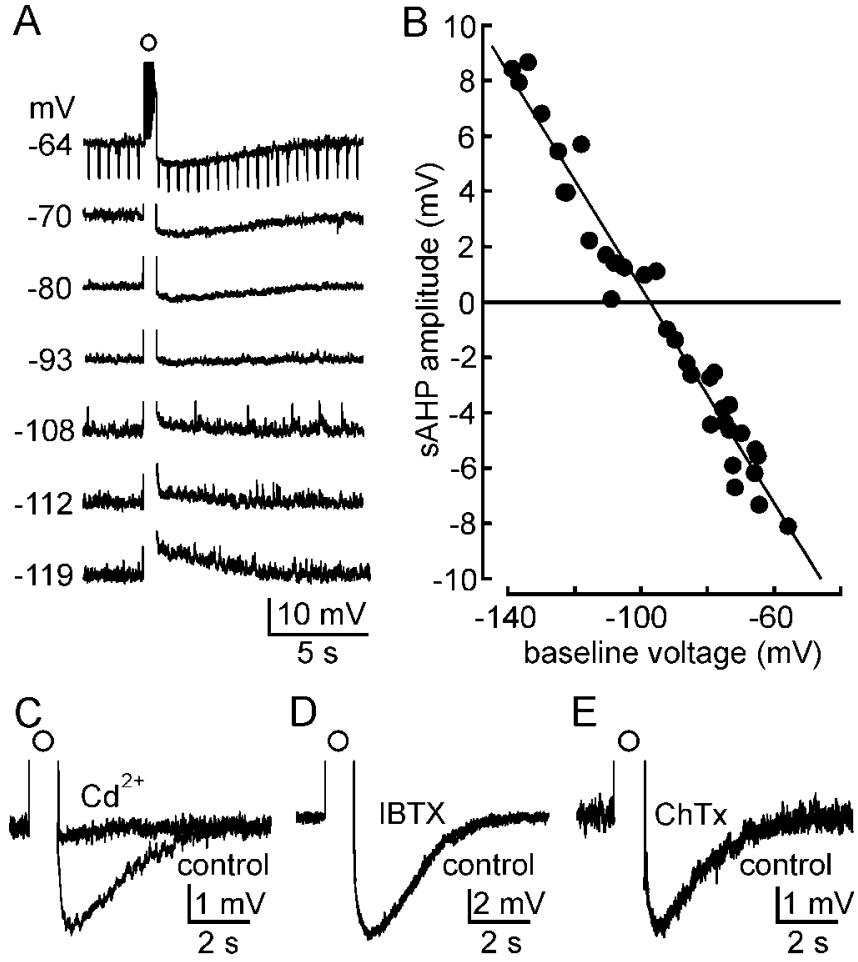

Figure 2. Properties of the SAHP in MNCs. A, Voltage traces recorded from an MNC maintained at different initial voltages (indicated on the left) in the presence of apamin and $\mathrm{Cs}^{+}$. Each trace shows the SAHP triggered by a train comprising 25 impulses. Note that the amplitude of the SAHP becomes smaller at more negative voltages and reverses polarity between -93 and $-108 \mathrm{mV}$. The vertical deflections in the top trace are hyperpolarizing responses to current pulses ( $-50 \mathrm{pA} ; 100 \mathrm{msec}$ ). Note that these responses become smaller during the AHP, indicating an increase in membrane conductance. $B$, Plot showing the amplitude of the SAHP (relative to baseline voltage) measured during multiple trials at different baseline voltages. Note that the amplitude varies linearly with voltage and reverses near $-100 \mathrm{mV}$. C $-E$, Traces show isolated sAHPs evoked by long trains under control conditions (i.e., in the presence of $\mathrm{Cs}^{+}$and apamin) and after adding $0.5 \mathrm{~mm} \mathrm{Cd}^{2+}(C), 80 \mathrm{~nm} \operatorname{IBTX}(D)$, or $200 \mathrm{~nm} \mathrm{ChTx}(E)$.

$(n=5)$. In contrast, in the same cells (Fig. 1C), the decay phase of the sAHP evoked by a long spike train in the presence of $100 \mathrm{nM}$ apamin and $5 \mathrm{mM} \mathrm{Cs}^{+}$was more than 10 times slower $(\tau=$ $2031 \pm 244 \mathrm{msec} ; p=0.001 ; n=5)$. Thus, the sAHP that follows long spike trains in MNCs is not attributable to a prolongation of the decay of the apamin-sensitive current but to the activation of a much slower and pharmacologically distinct conductance. Because the duration of the apamin-sensitive afterhyperpolarization is intermediate between the apamin-insensitive fAHP $(\sim 50$ msec) that follows a single spike (Kirkpatrick and Bourque, 1996) and the sAHP that follows a long spike train, we will refer to this posttrain event as the "medium" afterhyperpolarization (mAHP).

\section{Ionic properties of the isolated sAHP}

If the sAHP is generated through a change in the activity of ion channels rather than ion pumps or exchangers, it should be associated with a distinct change in membrane conductance. As illustrated in Figure $2 A$, the sAHP evoked in the presence of $5 \mathrm{~mm}$ $\mathrm{Cs}^{+}$and $100 \mathrm{~nm}$ apamin was associated with an increase in membrane conductance $(n=4)$, indicating that it was caused by ion channel activation. Moreover, the peak amplitude of the sAHP varied linearly as a function of holding potential (Fig. 2 B). Linear regression fitting of data obtained from four cells revealed a mean slope of $-0.23 \pm 0.06$ with $r^{2}$ values ranging between 0.964 and 0.996 . Thus, amplitude was effectively linearly related to baseline 
voltage between -140 and $-60 \mathrm{mV}$. These data also revealed that the sAHP reversed polarity at a mean voltage of $-101.8 \pm 2.3 \mathrm{mV}$ $(n=4)$ (Fig. $2 A, B)$, a value corresponding to the Nernst potential for $\mathrm{K}^{+}$ions $\left(E_{\mathrm{K}}\right)$ in our recordings conditions (Kirkpatrick and Bourque, 1996). These observations indicate that the sAHP is attributable to the activation of voltage-independent $\mathrm{K}^{+}$channels. As shown in Figure $2 C$, bath application of $0.5 \mathrm{mM} \mathrm{Cd}^{2+}$ inhibited the sAHP by $>80 \%$ (mean sAHP amplitude, $-5.42 \pm$ $0.68 \mathrm{mV}$ in control vs $-0.96 \pm 0.35 \mathrm{mV}$ in $\mathrm{Cd}^{2+} ; p=0.02 ; n=$ $3)$. We therefore conclude that the sAHP is caused by the activation of voltage-independent $\mathrm{K}_{\mathrm{Ca}}$ channels.

Previous studies have shown that, in addition to smallconductance (SK) apamin-sensitive channels, $\mathrm{K}_{\mathrm{Ca}}$ currents can be mediated also by large-conductance (BK-type) and intermediate-conductance (IK-type) $\mathrm{K}_{\mathrm{Ca}}$ channels (Bond et al., 1999; Sah and Faber, 2002; Vogalis et al., 2003). Because BK- and IK-type channels can be blocked by iberiotoxin (Garcia et al., 1991) and charybtodotoxin (McManus, 1991), respectively, we examined the effects of these drugs on the sAHP in MNCs. As illustrated in Figure 2, $D$ and $E$, the sAHP could not be blocked by bath application (15-25 min) of either 20-100 nM iberiotoxin (mean sAHP amplitude, $-7.6 \pm 1.2 \mathrm{mV}$ in control vs $-7.3 \pm 1.4$ $\mathrm{mV}$ in iberiotoxin; $p=0.52 ; n=5$ ) or $40-240 \mathrm{~nm}$ charybdotoxin $(-7.5 \pm 1.9 \mathrm{mV}$ in control vs $-8.2 \pm 1.9 \mathrm{mV}$ in charybdotoxin; $p=0.06 ; n=7)$. Although the $p$ value is close to the significance criterion $(p<0.05)$ in the latter comparison, it is important to note that the amplitude of the sAHP appeared to increase, if anything, and not to decrease, in the presence of toxin. In recordings from three cells, we tested the effects of the toxins in the presence of $0.01 \%$ BSA in an attempt to reveal an inhibitory effect that might have been prevented as a result of a lowering of the effective concentration by toxin binding to nonspecific sites in our perfusion apparatus. In two cases, the cells were tested with charybdotoxin, and in the other case, the cell was tested with iberiotoxin. Although the number of cells tested under these conditions precluded statistical analysis, none of the cells tested under these conditions showed any inhibition of the sAHP in the presence of toxin, and data from these cells were included in the numbers reported above. The sAHP recorded in MNCs in the presence of $\mathrm{Cs}^{+}$and apamin, therefore, is unlikely to be attributable to the activation of SK, BK, or IK channels.

\section{Activity dependence of the sAHP}

We next examined the activity dependence of the sAHP isolated by the presence of 3-5 $\mathrm{mM} \mathrm{Cs}^{+}$and $100 \mathrm{~nm}$ apamin. Trains of spikes of variable duration were evoked by depolarizing current pulses lasting 20-2500 msec. As shown in Figure 3A, the amplitude of the SAHP recorded in single MNCs increased as a function of the number of spikes evoked in each train. Data derived from seven cells (see Materials and Methods) revealed that sAHP amplitudes became statistically significant when the number of spikes in the train was greater than or equal to six (Fig. $3 B$ ). On a semilog plot (data not shown), the amplitude of the sAHP was found to change by $2.99 \mathrm{mV}$ per $e$-fold change in the number of impulses in the train $\left(r^{2}=0.983\right)$.

\section{Effects of muscarinic receptor activation on the isolated SAHP}

Because the apamin-insensitive sAHP represents a common target for modulation by muscarinic acetylcholine receptors in other types of neurons (Alonso et al., 1994; Bond et al., 1999; Sah and Faber, 2002; Vogalis et al., 2003), we examined the effects of muscarine on the sAHP isolated by $5 \mathrm{mM} \mathrm{Cs}^{+}$and $100 \mathrm{~nm}$ apamin
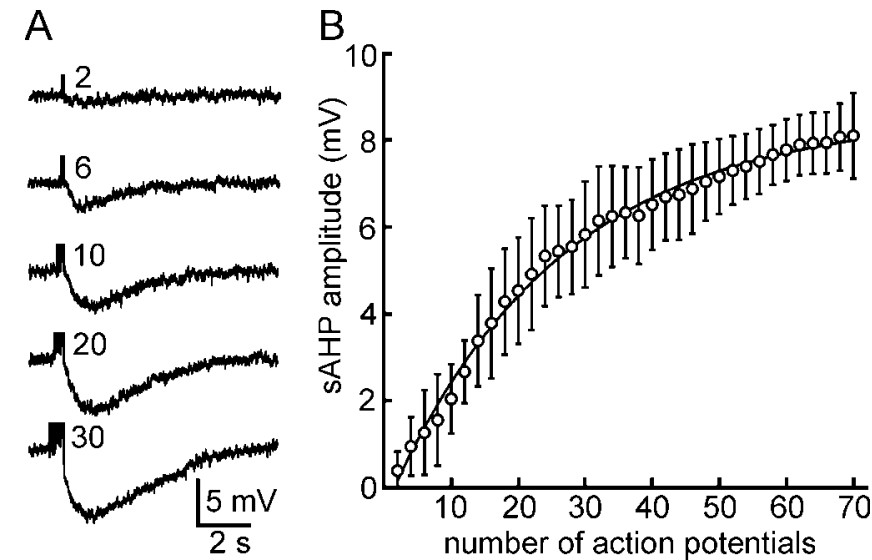

Figure 3. Activity dependence of the SAHP in MNCs. A, Traces showing SAHPs evoked by spike trains comprising different numbers of impulses (indicated next to each trace) in the presence of apamin and $\mathrm{Cs}^{+} . B$, Graph showing the average amplitude ( $\pm \mathrm{SD}$ ) of the sAHP recorded from seven MNCS as a function of the number of action potentials in the train. The amplitude of the SAHP becomes statistically significant when six or more spikes are evoked.

in 13 MNCs. As illustrated in Figure $4 A$, bath application of 4-100 $\mu \mathrm{M}$ muscarine caused a reversible inhibition of the sAHP $(-6.1 \pm 0.5 \mathrm{mV}$ control vs $-2.5 \pm 0.3 \mathrm{mV}$ muscarine; $n=13$; $p<0.001)$. The onset of the effect proceeded slowly, reaching a maximum 5-10 min after initial exposure to the drug (Fig. 4B). As expected, the inhibitory effect of muscarine was antagonized in the presence of $10-100 \mu \mathrm{M}$ atropine $(-5.0 \pm 0.8 \mathrm{mV}$ in atropine vs $-4.7 \pm 1.0 \mathrm{mV}$ in atropine plus muscarine; $p=0.24 ; n=$ 4) (Fig. $4 B, C$ ). Application of atropine itself was without effect, on average $(-6.7 \pm 1.4$ to $-6.7 \pm 1.5 ; p=0.93 ; n=6)$. The absence of significant effects on the sAHP of atropine alone may reflect the absence of a basal cholinergic tone under our specific experimental conditions and should not be taken to signify an absence of basal cholinergic modulation under physiological conditions in situ. To examine whether muscarine could affect both the MAHP and the sAHP, we characterized the kinetics of the muscarine-sensitive AHP by subtracting voltage traces recorded before and after muscarine in ACSF containing no apamin. As shown in Figure 4D, addition of muscarine under these conditions inhibited the late portion of the compound afterhyperpolarization but left an early component unblocked. The muscarine-sensitive component revealed by digital subtraction (Fig. $4 D$, bottom) showed a slow rising phase $(\sim 0.5 \mathrm{sec})$ and a mean time constant of decay of $1860 \pm 263 \mathrm{msec}(n=3)$, a value equivalent to that characterizing the sAHP recorded in the presence of $\mathrm{Cs}^{+}$and apamin $(\tau=2031 \pm 244 \mathrm{msec} ; p=0.665)$. Moreover, the mAHP evoked by a brief train (i.e., two to four action potentials) in the presence of $\mathrm{Cs}^{+}$alone was not significantly inhibited by muscarine $(-7.1 \pm 1.4 \mathrm{mV}$ vs $-5.7 \pm 1.2 \mathrm{mV}$ in muscarine; $p=0.139 ; n=4)$. Thus, muscarine selectively inhibits the sAHP and not the mAHP in MNCs.

\section{Muscarine does not affect spike parameters and depolarizing afterpotentials}

Because the sAHP reflects the activation of a $\mathrm{K}_{\mathrm{Ca}}$ conductance, its inhibition by muscarinic receptors might be attributable either to a modulatory effect on the relevant $\mathrm{K}^{+}$channels or to an effect on action potential-mediated $\mathrm{Ca}^{2+}$ influx. We therefore examined the effects of muscarine on various $\mathrm{Ca}^{2+}$-sensitive action potential parameters associated with spike trains evoked in the presence and absence of muscarine. As illustrated in Figure $5 A$, muscarine 
A
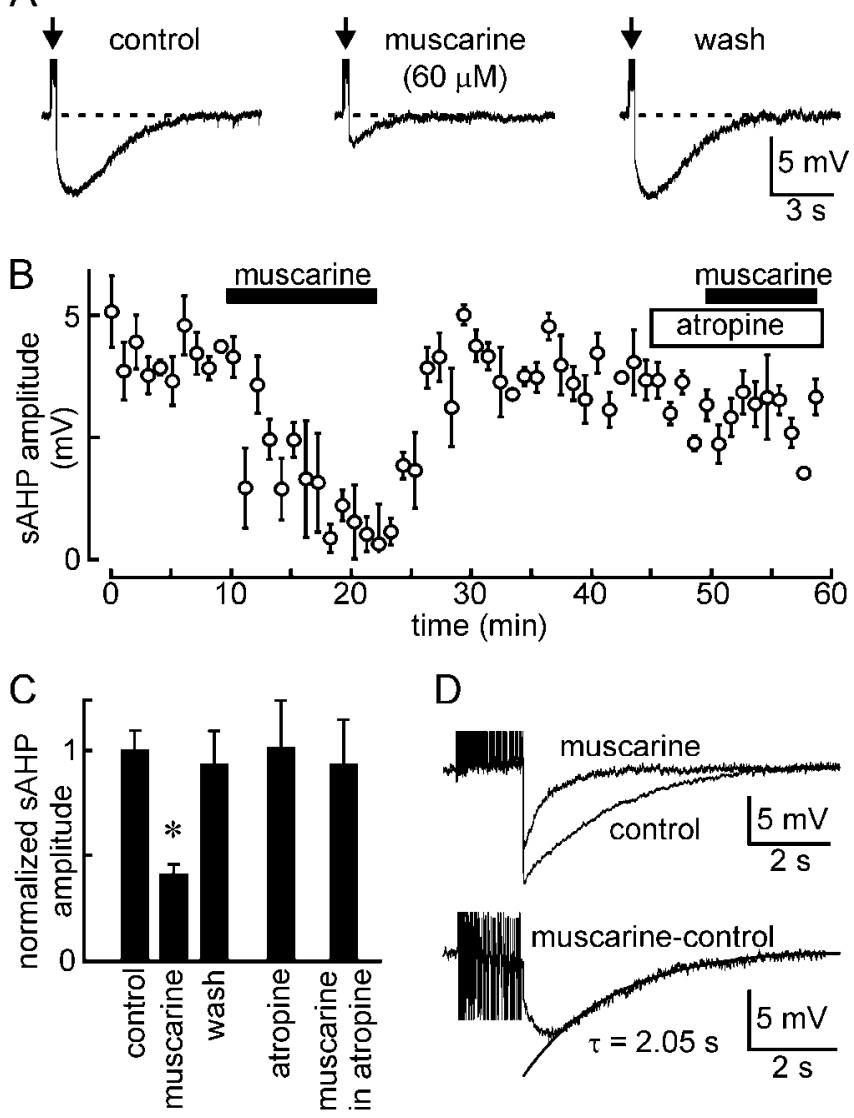

D
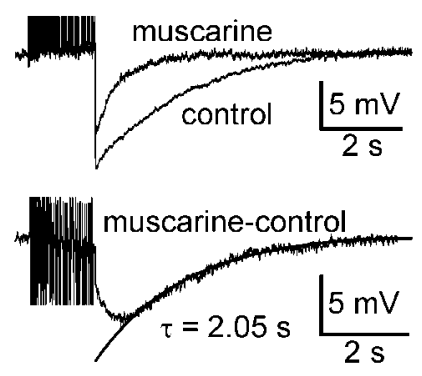

Figure 4. Muscarinic modulation of the SAHP in MNCs. A, Isolated SAHPs evoked by a train of 25 impulses evoked under control conditions (left), $10 \mathrm{~min}$ after bath application of $60 \mu \mathrm{m}$ muscarine (middle), and $10 \mathrm{~min}$ after washout of the drug (right). B, Time course of the effect ( \pm SEM) of muscarine $(60 \mu \mathrm{M})$ on the SAHP evoked by a train of 20 impulses applied in a different cell. Note that the inhibitory effect of muscarine is blocked in the presence of $40 \mu \mathrm{m}$ atropine. C, Bar graphs summarizing the effects of different conditions on SAHP amplitude ( \pm SEM) (values normalized to control amplitude; ${ }^{*} p<0.05$ ). D, Top, Two superimposed traces showing the combined AHP (mAHP plus SAHP; i.e., no apamin was present) induced by a long spike train under control conditions and in the presence of $50 \mu \mathrm{m}$ muscarine. The bottom panel shows the trace obtained when the top traces are digitally subtracted, thereby revealing the time course of the muscarine-sensitive AHP. Note the similarity in the rate of decay between the muscarine-sensitive AHP (a monoexponential fit is superimposed and the time constant $\tau$ is indicated) and the SAHP (Fig. 10).

did not visibly affect the shape of action potentials evoked under these two conditions. Quantification of data recorded from seven cells (Fig. 5B) confirmed a lack of significant effect on spike overshoot (i.e., absolute voltage at the peak of the action potential was $17.9 \pm 2.9 \mathrm{mV}$ in control vs $15.3 \pm 3.0 \mathrm{mV}$ in muscarine; $p=$ $0.29)$, action potential duration ( $1.50 \pm 0.28 \mathrm{msec}$ in control vs $1.53 \pm 0.28 \mathrm{msec}$ in muscarine; $p=0.61$ ), postspike fast afterhyperpolarization $(-17.2 \pm 1.8 \mathrm{mV}$ in control vs $-16.4 \pm 1.9 \mathrm{mV}$ in muscarine; $p=0.36$ ), or action potential broadening (192 \pm $11 \%$ in control vs $190 \pm 22 \%$ in muscarine; $p=0.86$ ). The effects of muscarine, therefore, are most likely because of a modulation of the $\mathrm{K}^{+}$channels responsible for the sAHP rather than a modulation of action potential-evoked $\mathrm{Ca}^{2+}$ influx. To further investigate the specificity of its actions, we also examined whether muscarine could affect the amplitude of summed DAPs. For these experiments, we evoked DAPs in the presence of $100 \mathrm{nM}$ apamin (to eliminate the $\mathrm{mAHP}$ ), and we used trains comprising two to four spikes to minimize the sAHP. Under these condi-
A

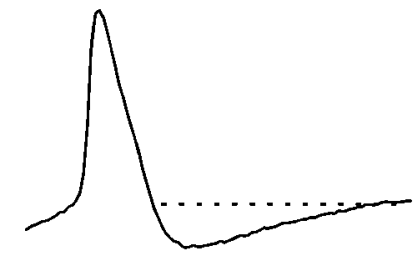

control
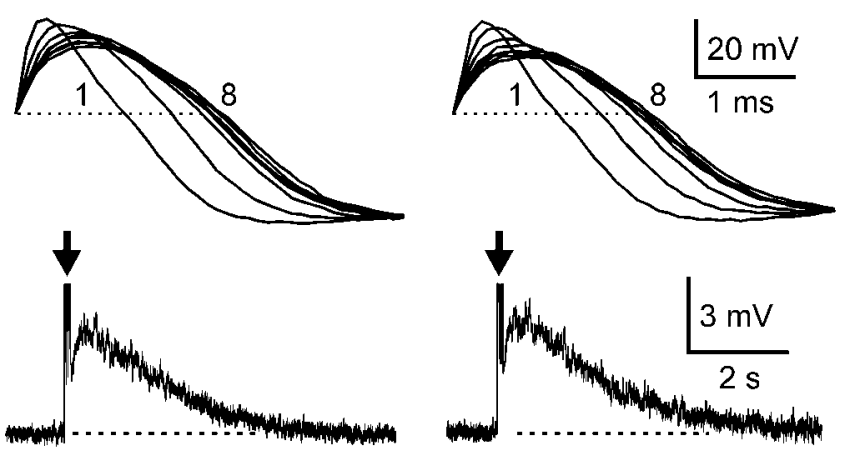

$\mathrm{B} \square$ control
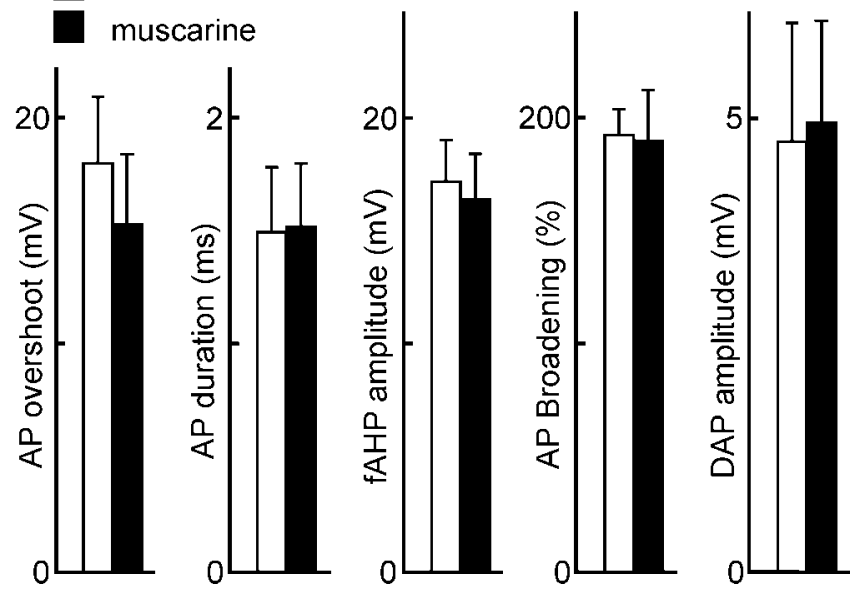

Figure 5. Muscarine does not affect other calcium-dependent spike parameters. A, Brief trains of eight action potentials were obtained from a single MNC under control conditions (left) and in the presence of $60 \mu \mathrm{m}$ muscarine (right). The traces illustrate the lack of obvious effect of muscarine on single action potential (AP) waveform (top, the first impulse in the train), the extent of spike broadening observed during the train (middle), and on the amplitude of the DAP that follows a short spike train (bottom, arrows). $B$, Bar graphs show mean values ( \pm SEM) derived for many spike parameters from a group of cells in control and muscarine. None of the values were significantly different $(p>0.05)$.

tions, bath application of muscarine did not significantly affect the amplitude of DAPs $(4.6 \pm 0.4 \mathrm{mV}$ in control vs $5.0 \pm 0.4$ in muscarine; $p=0.128 ; n=7$ ) (Fig. $5 B$ ).

Effects of muscarinic receptor activation on afterdischarges Previous experiments have shown that plateau potentials after brief trains of action potentials can lead to the generation of an afterdischarge when evoked from voltages within a few millivolts of spike threshold (Andrew and Dudek, 1984; Bourque, 1986). Although brief trains of action potentials do not significantly activate the sAHP (Figs. 1A,3), firing sustained during the afterdischarge would progressively activate the $\mathrm{K}_{\mathrm{Ca}}$ conductance responsible for the sAHP. Consequently, the sAHP may normally serve to restrict the steady-state amplitude of the plateau potential and the duration of the afterdischarge that can be sustained. 


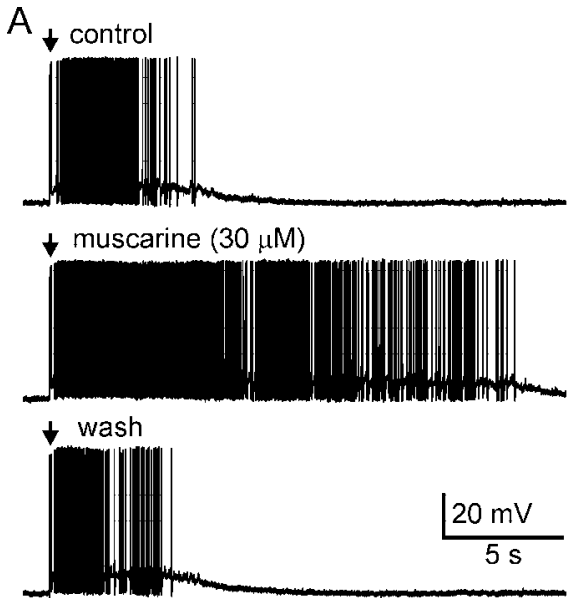

B

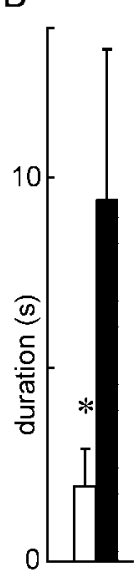

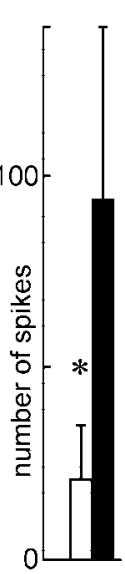

Figure 6. Effects of muscarine on afterdischarges in MNCS. A, Intracellular recordings showing the afterdischarges associated with plateau potentials evoked by triggering suprathreshold DAPs using a brief (4 impulses) current-evoked spike train (arrows) at a constant baseline voltage of $-58 \mathrm{mV}$. Traces show afterdischarges before (top), during (middle), and after (bottom) bath application of $30 \mu \mathrm{m}$ muscarine. $B$, Bar graphs summarize the quantification of afterdischarge-related parameters ( \pm SEM) measured in eight cells in the absence and presence of muscarine. ${ }^{*} p \leq 0.05$.

We therefore examined the effects of muscarinic receptor activation on these parameters. Because plateau potentials are activity and voltage dependent (Bourque, 1986; Li and Hatton, 1997), individual trials were evoked at intervals of $>20 \mathrm{sec}$ and from a constant baseline voltage near $-55 \mathrm{mV}$. As illustrated in Figure $6 A$, bath application of muscarine reversibly enhanced the duration of the afterdischarge. The time course of this effect was similar to the effects of muscarine on the sAHP (i.e., a maximum effect reached in 5-10 $\mathrm{min}$ ). The results of experiments performed on eight cells are summarized in Figure $6 \mathrm{~B}$. The mean \pm SEM duration of the afterdischarge increased from $1.8 \pm 1.0 \mathrm{sec}$ in control to $9.4 \pm 3.9 \mathrm{sec}$ in muscarine $(p=0.04)$. Moreover, this effect was associated with a significant increase in the peak amplitude of the plateau $(+4.4 \pm 0.3 \mathrm{mV}$ in control vs $+6.7 \pm$ $0.5 \mathrm{mV}$ in muscarine; $p<0.001$ ), in the number of action potentials present in the afterdischarge $(21 \pm 14$ in control vs $94 \pm 45$ in muscarine; $p=0.05)$, and in the steady-state firing frequency measured during the middle part of the afterdischarge $(6.5 \pm 3.7$ $\mathrm{Hz}$ in control vs $11.3 \pm 3.0 \mathrm{~Hz}$ in muscarine; $p=0.008$ ).

\section{Effects of muscarine on spontaneous phasic firing}

Previous studies have shown that phasic bursts in MNCs arise in part as a result of the establishment of a depolarizing plateau potential after temporal summation of the DAPs that follow spontaneous action potentials (Andrew and Dudek, 1984; Bourque, 1986; Bourque et al., 1998; Ghamari-Langroudi and Bourque, 1998). Because plateaus elicited by current-evoked spike trains are enhanced as a result of inhibiting the sAHP (Fig. 6), we examined the effects of muscarine on spontaneous phasic firing in eight MNCs. Bath application of 4-50 $\mu \mathrm{M}$ muscarine caused a small $(1.6-6.3 \mathrm{mV})$ depolarization of the membrane in all of the cells tested. In each of three cells in which spontaneous firing was absent or had been abolished by applying a constant hyperpolarizing current (maintained until after drug washout), this depolarization was sufficient to reversibly initiate phasic firing (Fig. 7A). In six cells, we compared the characteristics of bursts recorded in the presence of muscarine with those recorded from the same cells under control conditions but in which the baseline voltage was depolarized to match the value observed in the presence of muscarine (Fig. 7 A,B). Quantification of the data $\square$ control $\square \mathrm{mus}$ m

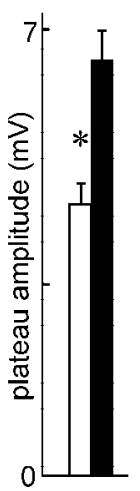

(Fig. 7C) revealed that mean burst length was significantly longer in the presence of muscarine $(23.5 \pm 7.6$ vs $5.7 \pm 2.6 \mathrm{sec}$ in control; $p=0.042)$. Moreover, the absolute plateau voltage detected during the steady-state part of phasic bursts was more depolarized in the presence of muscarine $(-49.4 \pm 2.4 \mathrm{vs}-52.0 \pm 2.0 \mathrm{mV}$ in control; $p=0.027$ ), and firing rate during the corresponding segments was enhanced $(5.7 \pm 0.5 \mathrm{~Hz}$ in muscarine vs $2.5 \pm 0.5 \mathrm{~Hz}$ in control; $p<0.001)$.

\section{Discussion}

The emergence of phasic firing (Harris et al., 1975; Brimble and Dyball, 1977) and the enhancement of firing rate and burst duration in phasically active neurons (Wakerley et al., 1978; Bourque and Renaud, 1984) optimizes vasopressin release from MNCs during hemorrhage, dehydration, and hyperosmolality. Although advances have been made in our understanding of the basis for phasic firing in MNCs (Roper et al., 2003, 2004), little is known of the mechanisms by which the expression or features of phasic firing might be regulated under physiological and pathological conditions. Synaptic potentials in phasically active MNCs are not temporally organized, and phasic bursts depend on the intrinsically generated plateau potentials that emerge from temporal summation of DAPs (Andrew and Dudek, 1984; Ghamari-Langroudi and Bourque, 1998). Although DAPs provide most of the depolarizing drive during plateaus, overlapping conductances can affect plateau amplitude by enhancing or shunting the DAP current (Kirkpatrick and Bourque, 1996; Ghamari-Langroudi and Bourque, 2000). Central control of phasic firing, therefore, likely involves modulation of voltage- and/or $\mathrm{Ca}^{2+}$-gated ion channels that interact to generate plateau potentials.

\section{Role of the mAHP in MNCs}

The mAHP in rat MNCs can be blocked by apamin (Fig. 1), a blocker of $\mathrm{K}_{\mathrm{Ca}}$ channels encoded by SK1, SK2, and SK3 genes (Kohler et al., 1996; Shah and Haylett, 2000; Strobaek et al., 2000). In situ hybridization has revealed very high levels of SK3 but undetectable levels of SK1-SK2 gene transcripts in supraoptic nucleus (Stocker and Pedarzani, 2000). Moreover, the apamin sensitivity of the mAHP in MNCs $\left(\mathrm{IC}_{50}=1.3 \mathrm{~nm}\right.$ ) (Bourque and Brown, 1987) is identical with that of homomeric SK3 channels $\left(\mathrm{IC}_{50}=1.4 \mathrm{nM}\right)$ (Hosseini et al., 2001). Thus, in contrast to the mAHP of hippocampal neurons, which appears to result from SK2 channels (Bond et al., 2004), the mAHP in MNCs may be attributable specifically to the expression of SK3 channels, as has been found in other types of neurons (Pedarzani et al., 2000; Hosseini et al., 2001; Wolfart et al., 2001). In phasically active MNCs, apamin attenuates spike frequency adaptation at burst onset and increases mean intraburst firing frequency (Kirkpatrick and Bourque, 1996). However, burst duration is reduced under these conditions, indicating that inhibitory modulation of SK channels in situ would not simultaneously enhance burst duration and intraburst firing rate, as is observed during physiological activation. Here, we showed that such an effect can be mediated by cholinergic modulation of the sAHP. 
A
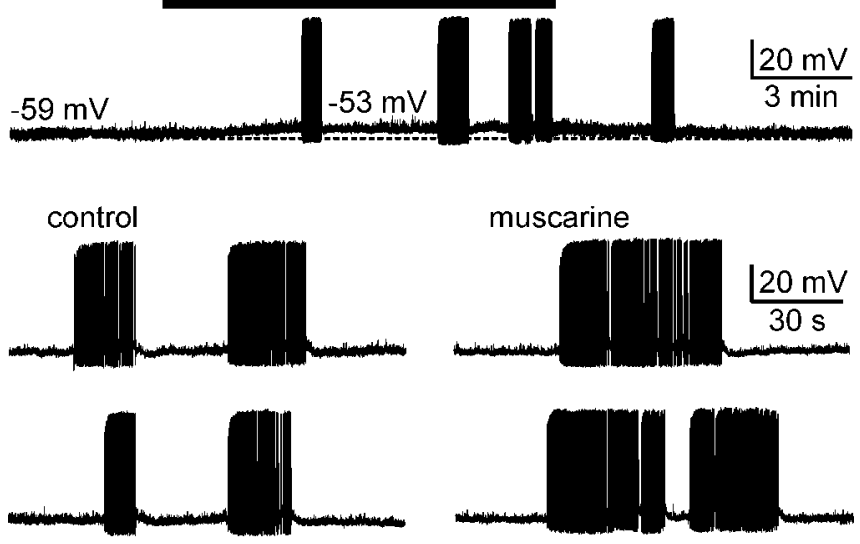

$V_{m}=-53 m V ; I=+20 p A$
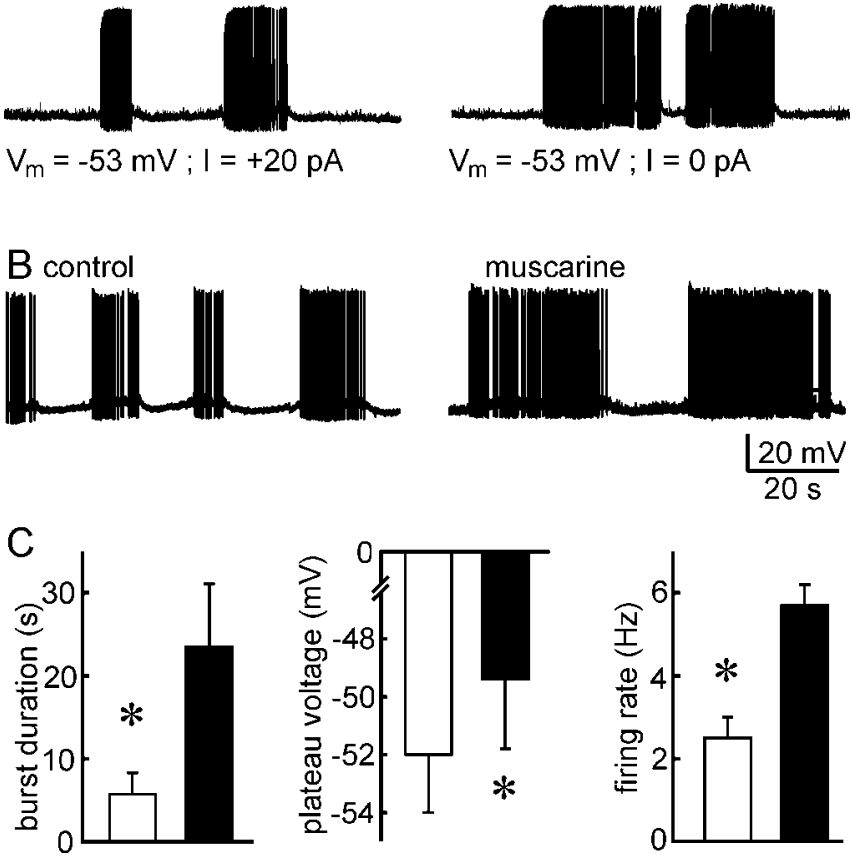

Figure 7. Effects of muscarine on phasic firing in MNCs. A, Top trace shows the effects of applying muscarine (bar) to a silent MNC. Note that the cell was depolarized and that phasic firing was induced. Four spontaneous bursts recorded from the same cell under control conditions while the initial baseline voltage was maintained at $-53 \mathrm{mV}$ are shown on the left and compared with bursts recorded at the same voltage in the presence of muscarine (right). $B$, Excerpt showing spontaneous phasic firing recorded from another neuron under control conditions (left) and in the presence of muscarine (right). The recording on the right was obtained from the same baseline voltage by continuous injection of hyperpolarizing current. Note that phasic bursts are more prolonged in the presence of muscarine. C, Bar graphs summarize the effects of muscarine ( \pm SEM) on the duration of phasic bursts (left), on absolute plateau voltage recorded during the steady-state phase of the burst (middle, even if baseline voltage was kept constant), and on mean intraburst firing rate (right). ${ }^{*} p<0.05$.

The sAHP in MNCs is not mediated by BK, IK, or SK channels Using pharmacological blockade of the mAHP (with apamin) and DAP (with $\mathrm{Cs}^{+}$), we revealed that the sAHP reflects activation of a $\mathrm{K}_{\mathrm{Ca}}$ current that is voltage independent between -140 and $-60 \mathrm{mV}$. Moreover, as reported by Greffrath et al. (1998), the sAHP was insensitive to IBTX, a potent blocker of BK type $\mathrm{K}_{\mathrm{Ca}}$ channels in MNC somata (Dopico et al., 1999). The sAHP in MNCs is therefore unlikely to be caused by the activation of BK channels, as it is in other neurons (Lancaster and Nicoll, 1987; Faber and Sah, 2002; Vogalis et al., 2003).

A previous study in MNCs (Greffrath et al., 1998) reported that the sAHP could be attenuated by $5-15 \mathrm{~nm}$ ChTx (a blocker of IK and BK channels). Because selective blockade of BK channels with IBTX was without effect, these authors suggested that IKtype $\mathrm{K}_{\mathrm{Ca}}$ channels might underlie the sAHP. In contrast, we ob- served no effects of ChTx on the isolated sAHP in MNCs, even when bath applied for $>20$ min at concentrations as high as 240 nM. In the experiments by Greffrath et al. (1998), the sAHP was not isolated from other afterpotentials, and ChTx always caused an enhancement of the DAP. It is therefore possible that inhibition of the SAHP in those experiments was caused indirectly by an enhancement of the superimposed DAP. Additional experiments will be required to determine whether $\mathrm{ChTx}$ enhances isolated DAPs and to investigate the basis for this effect, if present. Given the clear absence of inhibitory effects of ChTx on the isolated sAHP (Fig. 2E) and the apparent absence of IK-type gene expression in brain (Ishii et al., 1997; Joiner et al. 1997), we surmise that the sAHP is unlikely to be mediated by IK-type $\mathrm{K}_{\mathrm{Ca}}$ channels.

SK1-type channels originally expressed in Xenopus oocytes were found to be apamin insensitive and were thus presumed to underlie the sAHP (Kohler et al., 1996). However, subsequent studies revealed that toxin sensitivity is influenced by the expression system and that homomeric SK1 channels can be blocked by apamin (Shah and Haylett, 2000; Strobaek et al., 2000). Moreover, global suppression of SK channel activity via transfection of a dominant-negative construct (Villalobos et al., 2004) or using gene knock-out approaches (Bond et al., 2004) does not inhibit the sAHP in cortical neurons. These data argue strongly that the apamin-insensitive sAHP is not mediated by SK1 channels, a hypothesis supported here by the presence of a prominent sAHP in neurons purported to lack SK1 subunits (Stocker and Pedarzani, 2000). The molecular identification of channels underlying the sAHP in MNCs and other types of neurons remains to be established.

\section{Activity dependence of the SAHP in MNCs}

In contrast to the apamin-sensitive mAHP, which reaches peak amplitude after $\sim 15$ impulses (Kirkpatrick and Bourque, 1996), we found that the sAHP grows progressively over 70-100 impulses. Interestingly, intracellular $\left[\mathrm{Ca}^{2+}\right]$ also increases slowly at the onset of a burst in MNCs, reaching a maximal and sustained value only after 50-100 impulses have been discharged (Roper et al., 2004). The mAHP, therefore, may be mediated by channels having a higher affinity for $\mathrm{Ca}^{2+}$ than those underlying the sAHP. Alternately, channels mediating the sAHP could be located in a membrane domain spatially more distant than mAHP channels relative to the site of action potential-mediated $\mathrm{Ca}^{2+}$ entry. Indeed, in contrast to the mAHP, which begins to decay almost immediately after the end of a spike train (Fig. $1 B$ ), the sAHP continues to rise for as long as $1 \mathrm{sec}$ after the end of a train (Fig. 2C). However, Sah and Clements (1999) showed that sAHP channels in hippocampal neurons activate slowly even when $\left[\mathrm{Ca}^{2+}\right]$ is raised suddenly throughout the cell by photolytic release of caged calcium. Moreover, experiments in neocortical neurons have indicated that $\mathrm{mAHP}$ and sAHP channels may have a similar sensitivity to $\left[\mathrm{Ca}^{2+}\right.$ ], but that sAHP channel activation reflects changes in global cytoplasmic $\left[\mathrm{Ca}^{2+}\right]$ rather than submembrane $\left[\mathrm{Ca}^{2+}\right]$ change (Abel et al., 2004). Thus, the slower activation of sAHP channels could be attributable either to a spatial segregation of the channel subtypes involved or to a requirement for $\mathrm{Ca}^{2+}$ ions binding to a cytoplasmic intermediate before sAHP channel opening. Regardless of the basis for slower kinetics and reduced activity dependence, outward current carried by sAHP channels in MNCs likely grows slowly and progressively after burst onset and could therefore regulate both steadystate firing rate and the duration of phasic bursts. 


\section{Muscarinic receptors modulate sAHP and phasic firing}

Our results show that the isolated sAHP in MNCs is inhibited by atropine-sensitive (muscarinic) cholinergic receptors. Although the subtype of receptor responsible for this effect remains to be established, studies in other types of neurons have recently implicated $\mathrm{M}_{3}$ receptors (Rouse et al., 2000; Krause et al., 2002). In MNCs, muscarinic inhibition of the sAHP reversibly enhanced plateau potentials and firing rate during evoked afterdischarges. Similarly, experiments on phasically active MNCs showed that, in the presence of muscarine, plateau potentials reached more depolarized voltages, and that the duration and mean firing rate of spontaneous bursts were enhanced compared with control. Thus, the effects of muscarine on phasic firing mimic those that take place during physiological activation in vivo.

Interestingly, muscarine caused a small but consistent membrane depolarization of MNCs (Fig. 7A). Because DAP amplitude increases when evoked from more positive membrane potentials (Bourque, 1986), this effect would likely potentiate any muscarinic receptor-mediated enhancement of plateau potentials and phasic firing under physiological conditions. However, in our experiments, the muscarine-mediated enhancement of plateaus occurred even when the initial baseline voltage was adjusted to the control value by constant current injection. Thus, burst parameters can be upregulated directly through a selective inhibition of the SAHP, and this enhancement does not require a concomitant voltage-dependent enhancement of the DAP. Although additional experiments will be required to define the mechanism underlying muscarine-induced depolarization, this effect was presumably not caused by suppression of sAHP channels, because it could be observed in silent cells (Fig. 7A). Moreover, preliminary analysis indicates that the depolarization is not associated with a significant increase in membrane conductance (data not shown). Thus, the decrease in sAHP amplitude observed in the presence of muscarine is not simply attributable to a shunting effect. Indeed, if changes in sAHP amplitude simply reflected changes in membrane input resistance, one would expect to see proportional changes in other parameters (e.g., in the isolated DAP, mAHP, etc.), which was clearly not the case (Fig. 5). Thus, muscarinic effects on burst parameters are mediated through a specific modulation of the sAHP.

\section{References}

Abel HJ, Lee JC, Callaway JC, Foehring RC (2004) Relationships between intracellular calcium and afterhyperpolarizations in neocortical pyramidal neurons. J Neurophysiol 91:324-335.

Alonso A, Faure MP, Beaudet A (1994) Neurotensin promotes oscillatory bursting behavior and is internalized in basal forebrain cholinergic neurons. J Neurosci 14:5778-5792.

Andrew RD, Dudek FE (1984) Analysis of intracellularly recorded phasic bursting by mammalian neuroendocrine cells. J Neurophysiol 51:552-566.

Armstrong WE, Smith BN, Tian M (1994) Electrophysiological characteristics of immunochemically identified rat oxytocin and vasopressin neurones in vitro. J Physiol (Lond) 475:115-128.

Arnauld E, Cirino M, Layton BS, Renaud LP (1983) Contrasting actions of amino acids, acetylcholine, noradrenaline and leucine enkephalin on the excitability of supraoptic vasopressin-secreting neurons. Neuroendocrinology 36:187-196.

Bicknell RJ (1988) Optimizing release from peptide hormone secretory nerve terminals. J Exp Biol 139:51-65.

Bicknell RJ, Leng G (1981) Relative efficiency of neural firing patterns for vasopressin release in vitro. Neuroendocrinology 33:295-299.

Bioulac B, Gaffori O, Harris M, Vincent JD (1978) Effects of acetylcholine, sodium glutamate and GABA on the discharge of supraoptic neurons in the rat. Brain Res 154:159-162.
Bond CT, Maylie J, Adelman JP (1999) Small-conductance calciumactivated potassium channels. Ann NY Acad Sci 868:370-378.

Bond CT, Herson PS, Strassmaier T, Hammond R, Stackman R, Maylie J, Adelman JP (2004) Small conductance $\mathrm{Ca}^{2+}$-activated $\mathrm{K}^{+}$channel knock-out mice reveal the identity of calcium-dependent afterhyperpolarization currents. J Neurosci 24:5301-5306.

Bourque CW (1986) Calcium-dependent spike after-current induces burst firing in magnocellular neurosecretory cells. Neurosci Lett 70:204-209.

Bourque CW, Brown DA (1987) Apamin and D-tubocurarine block the afterhyperpolarization of rat supraopic neurosecretory neurons. Neurosci Lett 82:185-190.

Bourque CW, Renaud LP (1984) Activity patterns and osmosensitivity of rat supraoptic neurones in perfused hypothalamic explants. J Physiol (Lond) 349:631-642.

Bourque CW, Kirkpatrick K, Jarvis CR (1998) Extrinsic modulation of spike afterpotentials in rat hypothalamoneurohypophysial neurons. Cell Mol Neurobiol 18:3-12.

Brimble MJ, Dyball RE (1977) Characterization of the responses of oxytocin- and vasopressin-secreting neurones in the supraoptic nucleus to osmotic stimulation. J Physiol (Lond) 271:253-271.

Dopico AM, Widmer H, Wang G, Lemos JR, Treistman SN (1999) Rat supraoptic magnocellular neurones show distinct large conductance, $\mathrm{Ca}^{2+}$ activated $\mathrm{K}^{+}$channel subtypes in cell bodies versus nerve endings. J Physiol (Lond) 519:101-114.

Dreifuss JJ, Kalnins I, Kelly JS, Ruf KB (1971) Action potentials and release of neurohypophysial hormones in vitro. J Physiol (Lond) 215:805-817.

Dutton A, Dyball RE (1979) Phasic firing enhances vasopressin release from the rat neurohypophysis. J Physiol (Lond) 290:433-440.

Dyball RE, Tasker JG, Wuarin JP, Dudek FE (1991) In vivo intracellular recording of neurons in the supraoptic nucleus of the rat hypothalamus. J Neuroendocrinol 3:383-386.

Faber ES, Sah P (2002) Physiological role of calcium-activated potassium currents in the rat lateral amygdala. J Neurosci 22:1618-1628.

Garcia ML, Galvez A, Garcia-Calvo M, King VF, Vazquez J, Kaczorowski GJ (1991) Use of toxins to study potassium channels. J Bioenerg Biomembr 23:615-646.

Ghamari-Langroudi M, Bourque CW (1998) Caesium blocks depolarizing after-potentials and phasic firing in rat supraoptic neurones. J Physiol (Lond) 510:165-175.

Ghamari-Langroudi M, Bourque CW (2000) Excitatory role of the hyperpolarization-activated inward current in phasic and tonic firing of rat supraoptic neurons. J Neurosci 20:4855-4863.

Greffrath W, Martin E, Reuss S, Boehmer G (1998) Components of afterhyperpolarization in magnocellular neurones of the rat supraoptic nucleus in vitro. J Physiol (Lond) 513:493-506.

Harris MC, Dreifuss JJ, Legros JJ (1975) Excitation of phasically-firing supraoptic neurones during vasopressin release. Nature 258:80-82.

Hatton GI, Yang QZ (2002) Synaptic potentials mediated by $\alpha 7$ nicotinic acetylcholine receptors in supraoptic nucleus. J Neurosci 22:29-37.

Hatton GI, Ho YW, Mason WT (1983) Synaptic activation of phasic bursting in rat supraoptic nucleus neurones recorded in hypothalamic slices. J Physiol (Lond) 345:297-317.

Hosseini R, Benton DC, Dunn PM, Jenkinson DH, Moss GW (2001) SK3 is an important component of $\mathrm{K}^{+}$channels mediating the afterhyperpolarization in cultured rat SCG neurones. J Physiol (Lond) 535:323-334.

Ishii TM, Silvia C, Hirschberg B, Bond CT, Adelman JP, Maylie J (1997) A human intermediate conductance calcium-activated potassium channel. Proc Natl Acad Sci USA 94:11651-11656.

Joiner WJ, Wang LY, Tang MD, Kaczmarek LK (1997) hSK4, a member of a novel subfamily of calcium-activated potassium channels. Proc Natl Acad Sci USA 94:11013-11018.

Kawasaki H, Palmieri C, Avoli M (1999) Muscarinic receptor activation induces depolarizing plateau potentials in bursting neurons of the rat subiculum. J Neurophysiol 82:2590-2601.

Kiehn O, Eken T (1998) Functional role of plateau potentials in vertebrate motor neurons. Curr Opin Neurobiol 8:746-752.

Kirkpatrick K, Bourque CW (1996) Activity dependence and functional role of the apamin-sensitive $\mathrm{K}^{+}$current in rat supraoptic neurones in vitro. J Physiol (Lond) 494:389-398.

Kohler M, Hischberg B, Bond CT, Kinzie JM, Marrion NV, Maylie JA, Adelman JP (1996) Small-conductance, calcium-activated potassium channels from mammalian brain. Science 272:1709-1714. 
Krause M, Offermanns S, Stocker M, Pedarzani P (2002) Functional specificity of $\mathrm{G}_{\alpha q}$ and $\mathrm{G}_{\alpha 11}$ in the cholinergic and glutamatergic modulation of potassium currents and excitability in hippocampal neurons. J Neurosci 22:666-673.

Lancaster B, Nicoll RA (1987) Properties of two calcium-activated hyperpolarizations in rat hippocampal neurones. J Physiol (Lond) 389:187-203.

Li Z, Hatton GI (1997) Reduced outward $\mathrm{K}^{+}$conductances generate depolarizing after-potentials in rat supraoptic nucleus neurones. J Physiol (Lond) 505:95-106.

McManus OB (1991) Calcium-activated potassium channels: regulation by calcium. J Bioenerg Biomembr 23:537-560.

Pedarzani P, Kulik A, Muller M, Ballanyi K, Stocker M (2000) Molecular determinants of $\mathrm{Ca}^{2+}$-dependent $\mathrm{K}^{+}$channel function in rat dorsal vagal neurones. J Physiol (Lond) 527:283-290.

Renaud LP, Bourque CW (1991) Neurophysiology and neuropharmacology of hypothalamic magnocellular neurons secreting vasopressin and oxytocin. Prog Neurobiol 36:131-169.

Rhodes CH, Morrell JI, Pfaff DW (1981) Immunohistochemical analysis of magnocellular elements in rat hypothalamus: distribution and numbers of cells containing neurophysin, oxytocin, and vasopressin. J Comp Neurol 198:45-64.

Roper P, Callaway J, Shevchenko T, Teruyama R, Armstrong WE (2003) AHP's, HAP's and DAP's: how potassium currents regulate the excitability of rat supraoptic neurones. J Comput Neurosci 15:367-389.

Roper P, Callaway J, Armstrong WE (2004) Burst initiation and termination in phasic vasopressin cells of the rat supraoptic nucleus: a combined mathematical, electrical, and calcium fluorescence study. J Neurosci 24:4818-4831.

Rotter A, Birdsall NJ, Burgen AS, Field PM, Hulme EC, Raisman G (1979) Muscarinic receptors in the central nervous system of the rat. I. Technique for autoradiographic localization of the binding of $\left[{ }^{3} \mathrm{H}\right]$ propylbenzilylcholine mustard and its distribution in the forebrain. Brain Res 180:141-165.

Rouse ST, Hamilton SE, Potter LT, Nathanson NM, Conn PJ (2000) Muscarinic-induced modulation of potassium conductances is unchanged in mouse hippocampal pyramidal cells that lack functional M1 receptors. Neurosci Lett 278:61-64.
Sah P, Clements JD (1999) Photolytic manipulation of $\left[\mathrm{Ca}^{2+}\right]_{\mathrm{i}}$ reveals slow kinetics of potassium channels underlying the afterhyperpolarization in hippocampal pyramidal neurons. J Neurosci 19:3657-3664.

Sah P, Faber ES (2002) Channels underlying neuronal calcium-activated potassium currents. Prog Neurobiol 66:345-353.

Shah M, Haylett DG (2000) The pharmacology of hSK1 Ca ${ }^{2+}$-activated $\mathrm{K}^{+}$ channels expressed in mammalian cell lines. Br J Pharmacol 129:627-630.

Stocker M, Pedarzani P (2000) Differential distribution of three $\mathrm{Ca}^{2+}$ activated $\mathrm{K}^{+}$channel subunits, SK1, SK2, and SK3, in the adult rat central nervous system. Mol Cell Neurosci 15:476-493.

Strobaek D, Jorgensen TD, Christophersen P, Ahring PK, Olesen S-P (2000) Pharmacological characterization of small conductance $\mathrm{Ca}^{2+}$-activated $\mathrm{K}^{+}$channels stably expressed in HEK 293 cells. Br J Pharmacol 129:991-999.

Takahashi A, Ishimaru H, Ikarashi Y, Kishi E, Maruyama Y (2001) Opposite regulation of body temperature by cholinergic input to the paraventricular nucleus and supraoptic nucleus in rats. Brain Res 909:102-111.

Villalobos C, Shakkottai VG, Chandy KG, Michelhaugh SK, Andrade R (2004) $\mathrm{SK}_{\mathrm{Ca}}$ channels mediate the medium but not the slow calciumactivated afterhyperpolarization in cortical neurons. J Neurosci 24:3537-3542.

Vogalis F, Storm JF, Lancaster B (2003) SK channels and the varieties of slow after-hyperpolarizations in neurons. Eur J Neurosci 18:3155-3166.

Wakerley JB, Poulain DA, Brown D (1978) Comparison of firing patterns in oxytocin- and vasopressin-releasing neurones during progressive dehydration. Brain Res 148:425-440.

Wolfart J, Neuhoff H, Franz O, Roeper J (2001) Differential expression of the small-conductance, calcium-activated potassium channel SK3 is critical for pacemaker control in dopaminergic midbrain neurons. J Neurosci 21:3443-3456.

Xu Z, Torday J, Yao J (2003) Functional and anatomic relationship between cholinergic neurons in the median preoptic nucleus and the supraoptic cells. Brain Res 964:171-178.

Zaninetti M, Blanchet C, Tribollet E, Bertrand D, Raggenbass M (2000) Magnocellular neurons of the rat supraoptic nucleus are endowed with functional nicotinic acetylcholine receptors. Neuroscience 95:319-323. 